\title{
Rational and irrational processes in decision making: An economic perspective
}

\author{
Lacatus Maria Liana, \\ Bucharest University of Economic Studies, Teacher Training Department, Romania
}

\begin{abstract}
The paper presents important issues of decision making processes with an emphasis on rational and irrational components of these processes. After a short introduction outlining the need for a deeper understanding of rational and non-rational factors that affect the decisions people make, the rationality of people decisions in daily life is questioned and the role of non-rational factors such as intuition are analyzed. The economic understanding of the decision making process is presented and principles of rational decision-making are explained. Different methods used and recommended by economists in order to make decisions are presented and applied in different life situations in order to demonstrate their value in daily life. Special emphasis is put on factors such as imperfect information, illusion of control, or risk aversion that may affect the rationality of the decision making processes. In the final section of the paper the concept of bounded rationality is introduced and explained along with new theories in economics that are challenging the classic economic perspective on the decision making process.
\end{abstract}

Keywords. Decision, rational decision, decision making process, bounded rationality.

\section{Introduction}

Decision making processes are among the most important processes that characterize human reasoning and imply crucial consequences for human actions and well-being. Individuals have to make decisions every day. No matter whether apparently simple decisions such as what to wear, to eat, or to do in a free-time hour they might have, or more complex ones such as choosing a school, a profession, a partner, or a place to live, all decisions people make affect their lives. This is why there are no simple or complex decisions, all decisions are important, due to their consequences or possible consequences.

Decision making processes are an important subject of research in the field of mental health. Good decisions are sometimes called "healthy decisions" (Tracy, 2014) while poor decisions are considered "unhealthy" mainly due to the fact that they are related to poor real-life outcomes (Caceda et al, 2014). This research is focused on the bases of good decisions and the role of reasoning and experience in the decision-making process together with an analysis of factors that may affect people's capacity for making good decisions.

In mental health theories, indecision is sometimes related to ill mental health or mental illness. Anxiety, for example, can affect the decision-making capacity, making people confused, not trusting themselves. (Lobozzo Aman, 2012). This phenomenon can disconnect people from their decision-making abilities and make them avoid the decision or unable to conclude amongst pros and cons. But, indecision is not always a sign of a mental health challenge. Indecision also occurs when people can't make a decision at a moment because they need time to weigh alternatives or obtain additional information or advice. Sometimes they do not like the decision that seems to be the best one in the given conditions and want to find reasons for another decision or, simply, they want to delay making a decision waiting for something better. Dilemma situations in which all choices have unsatisfactory consequences also promote hesitation and delayed decision making (Simon, 1993). In this case, as well as in many other cases, we can't conclude that a particular reaction or behaviour such as hesitation makes the difference between mental health and mental health challenge or illness. Mental health can include both good healthy decisions and poor ones, depending on many factors and 
healthy thinking is only one of them.

\section{Rational, non-rational and irrational}

Decision-making processes are complex, involving choices and, in most situations, deliberation, weighting alternatives and evaluation. Basically, decisions are the results of specific processes of reasoning. Good decisions are usually considered rational even when they are not necessarily conclusions of the inferences or alternatives best valued according to relevant criteria in a situation. They are considered good because they have positive, desirable consequences. Similarly, poor decisions are often considered irrational. People tend to think that negative or undesirable consequences are the result of an insufficiently considered decision or of a decision made in the absence of sufficient or necessary information; in other words, they are the result of a lack of reasoning. Rational decisions seem to be the most appropriate way to come to desirable actions and consequences.

In fact, research concludes that in many circumstances people use non-rational factors, such as experience or intuition to make decisions and many of them consider such kinds of decisions good and valid based on the satisfaction they feel when applying and acting as a consequence of decisions they have made. Decisions based on experience or intuition are appreciated as well due to the rapid way in which they are made.

Intuition, defined as thoughts and preferences that come to mind quickly and effortlessly (Kahneman, 2002), represents one of the two-system operations that are involved in the decision making process. This is so called System 1 that leads to decisions being made automatically and rapidly. System 1 or intuitive judgment is different from System 2 or deliberate reasoning and the main difference is the way in which each system operates (see Fig.1): System 1is fast, associative, effortless, and difficult to control and modify; System 2 is slower, serial, requires effort, is deliberate, controlled and relatively flexible.

\begin{tabular}{|c|c|c|}
\hline \multirow{2}{*}{ Process } & $\begin{array}{c}\text { INTUITION } \\
\text { System 1 }\end{array}$ & $\begin{array}{c}\text { REASONING } \\
\text { System 2 }\end{array}$ \\
\cline { 2 - 3 } & Fast & Slow \\
\hline & Parallel & Serial \\
\hline & Automatic & Controlled \\
\hline & Effortless & Requires effort \\
\cline { 2 - 3 } & Associative & Rule-governed \\
\hline & Slow-learning & Flexible \\
\hline
\end{tabular}

Lecture,

https://www.nobelprize.org/uploads/2018/06/kahnemann-lecture.pdf

Figure 1: Intuition and reasoning

Due to the fact that people make hundreds and thousands decisions every day, in many cases, they do not have time to deliberate or make decisions in the most economically possible way: fast, automatically, effortless and associative. In other words, they make intuitive decisions. Rapid, automatic and effortless means also accessible in terms of psychology of choice. Accessibility is an attribute that indicates the easy way in which thoughts come to our mind (Kahneman, 2002). Intuitive thoughts are more accessible than deliberated ones and this explains also why intuitive decisions are more frequent than rational ones: intuitive thoughts come more easily and spontaneously to mind and make the decision making process effortless. 
At the same time, research has demonstrated that experienced decision makers who work under pressure rarely have to choose amongst alternatives or to deliberate. In their mind there is only one choice - the most accessible one, probably. The choices that were rejected are not represented. In these cases, experience is the basis of their decision. But, due to the fact that doubt is a phenomenon of System 2 and rapidity a characteristic of System 1, we could consider this also a non-rational decision, even is not exactly an intuitive one.

Intuition is considered to be a powerful decision making tool. Intuition is used not only in quick-decision situations but also when information is incomplete (Gigerenzer, 2001). Actually, in daily-life situations people often ignore some of the available information in order to make practical decisions. They rely on gut feelings that are the result of unconscious mental processes derived from the environment and previous experiences. Gut feelings are instinctive feelings (Sadler-Smith, 2007) and lead to good practical decisions.

In contrast to the rational analysis that implies evaluation of all possible factors, unconscious mental processes take into considerations only the most useful information. Efficient cognitive processes that ignore information represent what is called nowadays, heuristics (Gigerenzer, Brighton, 2009). Heuristics are mental "shortcuts" focusing on only one relevant factor in order to make a decision. They are time-savers and highly useful for making decisions in real-life situations. "Homo heuristicus" ignores part of available information in order to handle uncertainty and succeeds to do this efficiently. With less information he/she can make more good decisions. We could say that heuristics have a less-is-more effect that contrasts with the rational point of view. In accordance with the rational tradition, more information is always considered better. In the name of belief in the power of information and knowledge, rationalists try to make use of "total evidences" (Carnap, 1947) not leaving observations on record without using them (Good I.J., 1967). Economists have demonstrated that this is not always efficient. The search for information is costly in terms of time and money too and above a certain point the costs implied will exceed the benefits. At this point, the search should be stopped (Stigler, 1961). This is a rational conclusion: more information is not always better; sometimes less is more or, in other words, less information will lead to better heuristic decisions.

Heuristic decisions can be accurate despite the almost general belief that accuracy is positively related to effort. According to this belief, if a person invests more time to search out information and performs more computations, in other words, if his or her effort increases, the accuracy of the decisions he or she is making will increase too. Having limited time and being forced to make quick decisions, people have to trade-off between accuracy and effort. The accuracy-effort trade-off is considered a general law of cognition (Gigerenzer, Brighton, 2009). On the contrary, based on the less-is-more effect, heuristics lead to the conclusion that less information and computation allow higher accuracy and the mind does not necessarily need to trade-off between effort and accuracy. This trade-off is not generalized. There are situations in which with less information people are making decisions with higher accuracy and there is also a point above which more information or computation will decrease the accuracy.

The less-is-more effect and accuracy-effort trade-off are challenging the traditional perspective on rational decision making processes as processes of weighing all alternatives based on all available information. These situations are dependant on the environment more than on the mental processes themselves. This is why the rationality of heuristics is "ecological" not logical (Gigerenzer, Brigthon, 2009).

In the category of non-rational factors that affect decisions making processes, together with intuition and experience, research has identified many other important factors, such as social groups, asymmetrical reactions to gains and losses or anchors like analogical situations and actions. Non-rational decisions are the results of the need for rapidly made decisions, too 
rapid to allow for sequential analysis and evaluation of the situation. Another category of factors, usually, considered irrational, are emotions and all kinds of feelings. Traditionally, emotions were considered to be opposed to reason and reasoning and, as a consequence, seen as highly inappropriate for making rational decisions. Nowadays, psychologists recognize the important role of emotions in decision making processes. Actually, they point out that emotions are essential in decision making and have argued that reason is used only to justify the decision (Mercier, 2011). For entrepreneurs, for example, courage is essential to take the risks of starting a business and be independent or to come up with new products for the market. Actually, entrepreneurs are defined as courageous and determined persons.

\section{Rational from an economic perspective}

Decision making is a subject of real interest not only for psychologists, but for economists, too. Economics was traditionally defined as the science of rationality and rational decisions. The economic understanding of decision making is somehow different from the psychological one. When looking at decision making, economists understand rationality as a substantive (Simon, 1993), as something rational, while psychologists, as we have presented above, look at mental processes that take place in order to make a decision. From an economic perspective, the decision-making process is based on principles of rational decisions.

Principle 1. People have to make trade-offs. The first lesson of economics is that on the market nothing is free; people have to pay for everything. In order to have the things they need or want, people have to buy things and because they have limited income they can't buy everything. They have to make choices - to choose some things and to give up others. For example, if a person who has many obligations and has to make different monthly payments that, in total, are larger than his or her income, he or she may consider borrowing money from a bank to solve the problem. The credit is not free; the borrower has to pay interest. The interest is the cost of the credit. The alternative would be to use his or her own saved money. But this alternative has a cost too: the interest the person would get from the bank for the money in the deposit, would be given up. Or, in other words, the alternative to use the savings is also not free. With his or her income, the person has to choose to pay utilities, car and house insurance, to buy food, gasoline, car insurance, clothes, to buy tickets to the theatre or a monthly subscription to a club where he or she can spend the week-ends or swim in the evening. If the person chooses not to pay the club subscription, he or she gives up a pleasant and healthy recreation activity and this could affect their physical and mental health and, at the same time, increase future costs if the club will charge him or her more. Or, the person could choose to pay the car insurance later, but in this case the car cannot then be used for a period of time, the individual has to pay for public transportation and, maybe, also a penalty or give up the amount of money the insurance company would give him or her as bonus. No matter what decision the person makes, there will be costs to pay.

We do not know what decision a person will make in a given situation; this can vary from person to person and, for a person, from one situation to another depending on the importance given to each alternative at the time. People should not give up entertainment and recreation because they have to pay utilities or to buy food and insurance. Similar, communities should not give up a clean environment because this implies costs and will decrease their available money. But, knowing that trade-offs are necessary, people will be more able to make good informed decisions.

Principle 2: The cost paid by a person for a thing is another thing that the person has to give up. Because people have to make trade-offs, whenever a decision is made, it is rational for them to weigh existing alternatives and compare costs and benefits. In the case of a 
workshop on decision making issues, for example, the decision to take part in the workshop will have certain benefits, such as developing decision-making skills, meeting people with similar preoccupations and problems, making friends, the opportunity to join to an association or to plan future actions with the other participants. Among costs involved are travel and accommodation. These costs are evident. Some other costs are more or less hidden; for example, the time allocated to the workshop or activities given up in favour of the workshop are opportunity costs. An opportunity cost is the second best alternative to a decision or the choice that has not been taken. Actually, the opportunity cost is the best alternative that has been given up. Whenever a decision is made someone gives up something and as consequences, pays a cost. Opportunity costs are implicit costs.

It is rational in this case, when choosing among existing alternatives, for people to choose the one most valued. For economists to measure the value of an alternative means to establish the net value of the alternative, extracting costs from benefits. There are not only benefits or costs. Each alternative implies both costs and benefits and they should be weighed. It is rational to choose amongst alternatives with net benefits (benefits greater than costs) and to take the alternative with the highest net benefit. At a high level of costs, making decisions is difficult, even when benefits are greater than costs. But the real problem is not the level of the cost; it is the level of net benefit. Sometimes, there are no net benefits. In these cases it is rational to choose the alternative with the minimum loss. An increase in costs will change the decision if the cost will change the relative net values of alternatives.

Principle 3: Being rational is to make a marginal analysis rather than to think in terms of average. Real-life situations are rarely simply good or bad. Most of them are complex situations with advantages and disadvantages relative to specific goals and objectives a person might have. For example, a student who wants to be well prepared for exams has to allocate time to study. But, if he or she has more than one exam to prepare for and the available time is limited, the student has to decide how to distribute the time between different subjects taking into consideration the level of performance he or she is expected to achieve. One additional hour allocated to a subject will diminish the time available for another subject or another activity the student might want to have.

Changes involving one additional unit - one more hour to study psychology, one more class, one less hour to sleep, one more call with a friend or, if we are thinking of economic activity, one more worker hired by a firm, one more unit of a goods bought and consumed and so on - are called marginal. A person who makes a decision will better understand the consequences of one or another alternative in a given situation if he or she thinks at the margin analyzing what would happen if the situation would change step by step or if small changes will occur. Each additional step or small change will have a consequence in terms of benefits and costs / advantages and disadvantages that may be different from a step or a small change to another. A decision should be make taking into consideration these particular consequences of a small change.

Marginal analysis helps to make a decision about when to stop or continue an activity. For example, imagine an airline has to make a decision regarding the price of a domestic flight. If for this flight the company uses a plane with 125 seats and the total cost of a round trip will be 10000 euros the average cost per unit will be 10000 divided by 125 or 80 euros. In this case, the price per unit can't be less than 80 euros. At a lower price the company will have losses. Apparently this is a correct judgment. And it is correct if we accept that we should think in terms of average and make decisions based on average measurements. But, if we make a marginal analysis and establish what will happen when one more ticket is sold we will see that if the airline wants to have more income per flight it should not keep the price above 80 euros in any circumstances. If at a price higher than 80 euros 100 tickets have been sold, it is likely that if the company decreases the price, more tickets will be sold. With each 
additional ticket sold at a lower price, the company will increase its income per flight with the price of additional ticket sold. Economists say that the price of each additional ticket sold is, for the company, a marginal income earned or, speaking in more general terms, a marginal benefit. With each additional ticket sold the costs will increase too, but additional or marginal cost will be lower than the average cost due the fact that the plane will fly whether all the seats are sold or not. For each flight there are some fixed costs and some variable costs. The fixed costs, such as salaries of the employees (pilot, flight attendants, and so on) or airport taxes will stay at the same level. Only the variable costs, such as fuel, food or beverages served to passengers will increase. What really counts in this case is the difference between additional income earned by selling one more ticket (marginal income or revenue which is the marginal benefit) and additional costs implied by transporting one more passenger (marginal cost). If it is positive, in other words if the marginal revenue is higher than the marginal cost, the decision to sell tickets at lower prices is a good one; the company is better-off. The real problem is not if the price should be decreased, but how much it should be decreased. The answer is up to the level of marginal cost. If the price (marginal revenue) is higher than marginal cost, the difference is a gain; the company has additional profit. If the price (marginal revenue) is equal to an additional marginal cost, there is no additional profit, but there will be other benefits, such as loyal customers.

Marginal analysis helps understanding the "mystery" of flights tickets. The airlines make calculations on the total costs and estimations regarding the total income in order to function efficiently. Based on these calculations they establish the prices, different prices for categories of seats. They expect to sell the cheaper tickets first and then the more expensive ones. They also expect a certain number of tickets not to be sold. For these last ones, they might decrease prices at very last moment. It is rational to make such a decision. The rationality in this case means to increase the revenue or benefits. Low-cost companies have identified ways to decrease the costs such as maximum usage of available space in the plane or giving up serving free food or beverages to the passengers. They made a trade-off between the seat number and the available space per seat - more seats, less space per seat - and additional charges for luggage.

Marginal analysis is based on weighing marginal benefits (revenue) and marginal costs. The "golden rule" regarding making decisions is:

- - If, as consequence of a decision made, marginal benefits are higher than marginal costs occurring, the decision was good; it should have been made.

- - If, as consequence of a decision made, marginal benefits are lower than marginal costs occurring, the decision was bad; it should not have been made. The person who made this decision should give up.

Principle 4: People respond to incentives. As we have explained above, people making decisions weigh costs and benefits. Changes in costs and benefits will lead to changes in people's decisions and behaviours. This is a result of incentives that motivate people. For example, a producer who increases prices of his or her products will normally expect a decrease in the quantity sold. It is the effect of an important economic law - the law of demand. As the price of a good or service increases the quantity demanded decreases. In other words, price and quantity demanded are negatively related. The price impact on consumers can be explained through a cost-benefit analysis: at the same benefits estimated by the consumers, the costs will be higher. As consequence, the net benefit will decrease and consumers will give up to buy the more expensive things.

\section{Economic models of decision making}

Economists use and recommend different models and methods of decision making. All 
of them imply analysis such as cost-benefits analysis, weighing advantages/benefits and disadvantages/costs, alternatives net value according with established criteria calculation. A rational decision is made following some steps: identifying existing opportunities, defining the compromises needed to be made, calculating the costs to be paid and benefits that can be gained.

One of the most popular models is the decision-making matrix that implies five steps each decision maker has to follow: Step 1: The problem. The first and the most important step is to clearly define the problem that has to be solved. In the absence of a clear understanding of the problem that requires a decision, the decision could be wrong. Step 2: The alternatives. Alternatives represent possible solutions of the problem. Actually, they are the choices the decision makers have. Sometimes there are only two choices, but it is better to have more than two. Economists do not believe that there are situations when a person has no choices and he or she is forced to take whatever seems apparent. They say that a so called no-choice -situation is, in fact, an excuse for not taking a totally unattractive alternative. It is, for example, like when you have to choose between a chocolate cake and a bad apple and, of course, you choose the chocolate cake because you have "no alternative". Step 3: The criteria. Criteria have to be oriented to specific goals and to target whatever a person is expected to achieve. Sometimes is recommended to rank the criteria in order to see differences between alternatives. Step 4: The evaluation. Each alternative has to be evaluated according to the listed criteria. In order to establish the net value of each alternative, it is recommended to use numeric values, such as +1 or -1 depending on how much they meet a criterion and if they meet it or not. Depending on the number of criteria, for each alternative there will be a number of numeric values to be cumulated. The sum will be the net value of the alternative. For example, in the case of two criteria, an alternative will get +1 for conformity with one criterion and -1 for non-conformity with the other one and the net value will be $0(+1-1=0)$ Step5: The decision. It is rational to take the alternative with the highest net value. In the case of two or more alternatives with the same net value, more criteria can be added and the process of evaluation repeated. In the end one alternative will have the highest net value and these will be the decision.

A matrix such as the one presented in Figure 2 helps in decision-making. All existing alternatives can be listed in a column. For each alternative there can be one row in the matrix. All criteria should be be listed too. For each criterion there will be one column in the matrix. A separate column will be allocated for the net value of each alternative.

\begin{tabular}{|r|l|l|l|l|l|}
\hline The criteria & C1 & C2 & C3 & C4 & The net value \\
\hline The alternatives & & & & \\
\hline A1 & & & & \\
\hline A2 & & & & \\
\hline & & & & \\
\hline
\end{tabular}

Figure 2: The decision making matrix

The matrix can be used to make decisions in economic situations as well as in other 
specific domain- or real-life situations. For example, a person who wants to start a business has to make a decision regarding what to produce or in what industry to invest. (1) The problem: What will the firm produce? What business to start? (2) The alternatives: A1. Car wash; A2. Electronics; A3. Beekeeping; A4. House cleaning. (3) The criteria: C1. Qualification; C2. Market demand; C3. Expected profit; C4. Work satisfaction. (4) The evaluation: each alternative will receive grades from 1 to 5 depending on how much it meets each criterion $(5=$ much; $1=$ little). The decision making matrix could be like one represented in Figure 3 in case of a person with a university degree with major in information and communication technology.

\begin{tabular}{|l|c|c|c|c|c|}
\hline $\begin{array}{l}\text { The criteria } \\
\text { The alternatives }\end{array}$ & Qualification & $\begin{array}{c}\text { Market } \\
\text { demand }\end{array}$ & $\begin{array}{c}\text { Expected } \\
\text { profit }\end{array}$ & $\begin{array}{c}\text { Work } \\
\text { satisfaction }\end{array}$ & The net value \\
\hline Car wash & 1 & 2 & 2 & 2 & 7 \\
\hline Electronics & $\mathbf{2}$ & $\mathbf{3}$ & $\mathbf{3}$ & $\mathbf{3}$ & $\mathbf{1 1}$ \\
\hline Beekeeping & 1 & 3 & 3 & 3 & 8 \\
\hline House cleaning & 1 & 1 & 1 & 2 & 5 \\
\hline
\end{tabular}

Figure 3: The decision making matrix for an entrepreneur who wants to start a business

\section{Bounded rationality}

In decision making processes regarding economic activity factors interfere which are not related to the decision makers' rationality. Strictly speaking, the idea of rationality implies information. In other words, a rational decision is made if the decider has complete information about existing alternatives in order to choose the best. Economically speaking, he or she is perfectly informed. But, in reality, things are not always as they are supposed to be. Usually, in reality, people do not have complete information and, as a consequence, they are not perfectly informed. They are making decisions which are not necessarily irrational, strictly speaking, but are not a result of a process of deliberation or carefully analyzing a situation and weighting benefits and costs. Neuro-psychologists would say that such kinds of decisions are, as a fact, the results of a sort of "economical" way of functioning for the human brain which is searching for "short-cuts" and "the easiest ways" to process information and this kind of rationality is more like a "limited rationality" due to the mix of rational and non-rational factors. Among the last ones are mentioned an (1) exaggerated self-esteem, (2) the origin of money, (3) loss aversion or (4) familiarity.

1. (1) Exaggerated self-esteem. People tend to see themselves as better than they really are. They tend to believe that they are doing things better than they really do. No matter what decision is made, the decision-making process implies a certain level of confidence in the person's capacity to understand risks and benefits. However, exaggerated confidence and the illusion of loss of control can lead to a bad decision and, as a consequence, can cause greater losses. Having to choose between a car an an airplane, many people choose the car because they believe that driving is safer than flying despite the fact that there are enough data demonstrating that flying is much safer. Similarly, many people choose to start a business despite the fact that there are many arguments which indicate that this is a bad decision, such as the high number of firms that are closing every year. Exaggerated self-esteem may also be attributed to the CEO's who believes that they can do everything 
and make risky decisions and act at limit or, even worse, beyond limits and because of their risky behaviours the firm collapses. The same situation is in the case of the CEO who does not want to admit that the firm is having difficulties, despite the evidence, and, instead of acting in the direction of trying to correct the situation, they do things that will make it worse.

One could believe that in time, by becoming more experienced, people will gain a better understanding of their own capabilities. But, research has demonstrated that exaggerated self-esteem does not diminish in time, possibly also because people have different memories and attitudes when it comes to success and failure. Usually, people tend to remember successful actions as resulting from their intelligence and skills, while failures are considered to be caused by forces out of their control. In many failure situations they think that, with a little luck, next time things will be better.

1.(2) Where the money comes from. From an economic perspective, it doesn't matter where the money comes from. People make decisions no matter if they involve money gained through their own work or received as a gift or inheritance. The gift money or money gained by gambling is more easily spent than earned money. Similarly, money gained by gambling is easily risked gambling again while earned money is usually more carefully staked in playing games by chance. For example, an investor who has invested 10,000 euros in the stock market, gained 100,000 euros, and then lost 105,000 euros in another less profitable investment would probably consider that he has lost only 5,000 euros. People do not really consider their own property as things they did not pay for. The sorrow felt by giving up a thing of ones own is greater than the joy felt by buying that thing. Economically speaking, the price elasticity of demand can change when the consumer is emotionally attached to the good and experiences the ownership. The demand becomes less elastic. Buyer decisions can be influenced by the sense of ownership, even temporarily, and before a product is bought. If the consumer can be convinced to take home the product and to try it, the probability that he or she will buy the product increases because of the feeling of loss he or she will have if they then don't buy and rather give up the product. Sellers count on people's attachment to goods and their sense of ownership when they encourage buyers to take things home to try them, "to see how they look", or "to buy now and pay later".

2. (3) Loss aversion. People's concern about risks and losses is greater than the satisfaction of possible gains. If an investor chooses to sell stocks and invest in real estate he or she will be more affected if the stock prices increase than if the real estate market performs perform better. People's reactions towards loss and gain are different even if these are equal. For example, if a price of 1.5 euro for 1 litre of gas is expected to increase up to 2 euros the amount of 0.5 euros will be perceived as a loss and if the same price is expected to decrease up to 1 euro the same amount of money will be perceived as a gain. Although the the loss and the gain are equal ( 0.5 euros), the sorrow felt in the case of the loss is greater than the joy felt in the case of the gain. Further, the sorrow will be greater if the buyer feels that he or she is treated unfairly. People have a sense of justice and reject things they perceive as unfair, reacting negatively when considering that someone is taking advantages of them. From the buyer's perspective, an unfair situation would be, for example, an increase in the price of shovels in winter time after a strong snowfall or of food in a region affected by floods.

3.(4) Familiarity. When people have to make decisions without being perfectly informed, they choose, in many cases, based on familiar things, although this is not what economic theories recommend. Familiarity may lead to apparently irrational decisions mainly because unknown things that may be of value are not taken into consideration. Nowadays economists consider that peoples' rationality is not absolute, but limited or bounded. Bounded rationality is a more appropriate concept to describe human rationality (Simon, 1992) and the rationality of economic actions. 


\section{Conclusions}

From an economic point of view, a rational decision is made following some steps: identifying existing opportunities, defining compromises needed to be made, calculating the costs to be paid and benefits that can be gained. Rational decisions are based on understanding the human way of thinking and behaving and taking into consideration human characteristics and constraints that limit people's actions. Decision makers should take into consideration that people respond to incentives, have to make trade-offs, pay opportunity costs, choose amongst alternatives and give up alternatives, identify consequences, and think at margins or with respect to small changes. At the same time, in order to make more accurate decisions they should think at the margins. Marginal analysis implies weighing marginal costs with marginal benefits based on a 'golden rule' that says: "If, as consequence of a decision, marginal benefits are greater than marginal costs, the decision was good; it should be made. But, if as consequence of a decision, marginal benefits are smaller than marginal costs, the decision was wrong; it should not be made."

In real-life situations and, sometimes, in economic situations, decision makers do not always have all the information available at the time or in the time needed to deliberate or follow the steps recommended by economists for a rational decision. Heuristics helps to make good and accurate decisions despite the reality that a lot of information may be ignored in the decision making process. The efficiency of heuristics in decision making, including economic decision making is recognized nowadays by economists, too. They admit that our rationality is bounded and the perfect conditions implied by absolute rationality do not exist in reality.

\section{REFERENCES}

Caceda at al. (2014). Toward an understanding of decision making in severe mental illness. The Journal of Neuropsychiatry and Clinical Neurosciences. 26:3. (pp. 196-213). Retrieved from https://neuro.psychiatryonline.org/doi/abs/10.1176/appi.neuropsych.12110268

Gigerenzer, Gerd. Brighton, Henry. (2009). Homo heuristicus: Why biased minds make better inferences. Topics in Cognitive $\quad$ Science 1 (pp.107-143). $\quad$ Retrieved from https://onlinelibrary.wiley.com/doi/epdf/10.1111/j.1756-8765.2008.01006.x

Gigerenzer, Gerd. (2001). Rethinking rationality. In Gigerenzer, Gerd. Selten, Reinhard (Eds.) Bounded rationality: The adaptive toolbox. London: MIT Press (pp. 1-12). Retrieved from https://books.google.ro/books?hl=en\&lr=\&id=dVMq5UoYS3YC\&oi=fnd\&pg=PR9\&ots=p021-GGKV_\&sig=0F 3WNg2ERpdC7Rx86bFW5cU1NA0\&redir_esc=y\#v=onepage\&q\&f=false

Kahneman, Daniel. (2002). Maps of bounded bationality: A Perspective on intuitive judgment and choice. Prize Lecture, December 8, 2002, Retrieved from https://www.nobelprize.org/uploads/2018/06/kahnemann-lecture.pdf

Lobozzo Aman, Jodi. (2012, December 5). How to deal with anxiety-style decision and indecision [Blog post]. Retrieved from https://www.healthyplace.com/blogs/anxiety-schmanxiety/2012/12/decisions-made-or-not-made-anxiety-style

Mercier, Hugo; Sperber, Dan. (2011). Why do humans reason? Arguments for an argumentative theory. Behavioural and Brain Sciences, 34 (pp. 57 -111). doi: 10.1017/S0140525X10000968. Retrieved from https://www.dan.sperber.fr/wp-content/uploads/2009/10/MercierSperberWhydohumansreason.pdf

Sadler-Smith, Eugen. (2007). Incorporating intuition into HRD: Conceptual framework and practical suggestions for individual and organisational learning. Refereed Paper. Retrieved from https://www.ufhrd.co.uk/wordpress/wp-content/uploads/2008/06/507-incorporating-intuition-into-hrd_sadler-sm ith.

Selten, Reinhard. (2001). What is bounded rationality? In Gigerenzer, Gerd \& Reihhard Selten, Reinhard (Eds.) Bounded rationality: The adaptive toolbox (pp. 13-36). London, UK: MIT Press. Retrieved from 
https://books.google.ro/books?hl=en\&lr=\&id=dVMq5UoYS3YC\&oi=fnd\&pg=PR9\&ots=p021-GGKV_\&sig=0F 3WNg2ERpdC7Rx86bFW5cU1NA0\&redir_esc=y\#v=onepage \&q\&f=false

Simon, Herbert A. (1993). Decision making: Rational, nonrational, and irrational. In Educational Administration Quarterly, 29:3 (pp. 392-411). http://digitalcollections.library.cmu.edu/awweb/awarchive?type=file\&item=34170

Simon, Herbert A. (1972). Theories of bounded rationality. In B.C. McGuire \& Ron Radner (Eds). Decision and organization: A volume in honour of Jacob Marschak (pp. 161-176). North-Holland Publishing House, Retrieved

fromhttp://innovbfa.viabloga.com/files/Herbert_Simon__theories_of_bounded_rationality__1972.pdf

Tracy, Natasha. (2014, May 6). Unimportant decisions and bipolar depression [Blog post]. Retrieved from https://www.healthyplace.com/blogs/breakingbipolar/2014/05/unimportant-decisions-and-bipolar-depression 